for the first twenty-four hours, fell rapidly to negligible proportions, the locusts losing 45 per cent of their radioactivity during that period.

Auto-photography of adult locusts given is fortyeight-hour radioactive feed showed a concentration in the metathoracic pair of legs and in the ovaries and testes. The wings appeared to hold no phosphorus-32, as distinct from those adults, reared from radioactive hoppers, the wings of which showed up clearly on the films. This difference would permit double marking ' with the same isotope of both hoppers and adults within a given population.

In view of the fact that locust hoppers cast their skins frequently, external marking is of no use. This being so, there is no adequate marker available other than a radioactive isotope, and for work where a $\beta$-ray is sufficient, phosphorus with a half-life of $14 \cdot 3$ days is the most suitable element. There is no difference in the absorption of it by a hopper whether it is given in an organic state in grass and maize made radioactive or as an inorganic salt in bran. The bran feed is the obvious method of choice in the field, and large numbers of first- and second-instar hoppers can thus be made radioactive at comparatively low cost. Much could be learnt about hopper movement and death-rate by this method, the only one at present available. Its use, however, would entail the expenditure of much time and labour by specialized staff using costly apparatus. An attempt was made to circumvent this by an approach to Messrs. Kodak, Ltd., with the object of obtaining a $\beta$-ray-sensitive $8 \mathrm{~mm}$. film trace, suitably insulated and of known length, which could be laid in the track of advancing hoppers. With random sample counts taken over this for fixed periods, subsequent developing would show the passage of radioactive hoppers. Unfortunately, this method is so far inapplicable for $\beta$-rays, as there is no strip sufficiently sensitive for so short $a$ traverse. For the present, therefore, orthodox methods, involving capturing hoppers with a net and scanning the bag with a Geiger counter, would have to be used, though direct scanning of hopper concentrations could possibly be undertaken at night. Future developments in the direction of using a portable scintillation counter, with material emitting $a_{0} \gamma$-ray, may simplify this.

Unless some automatic recording device can be found, it seems that for labelling adult locusts radioactive isotopes have no advantages over the welltried colour paints, with which adults have been marked in the past for observing dispersal ${ }^{2}$. Untrained workers can see and record these, whereas radioactive locusts demand highly skilled technicians using special apparatus.

I wish to thank the following members of the University of Cape Town who gave me facilities : Prof. J. Day, Department of Zoology ; Dr. A. M. Cormack, Department of Physics, for much technical advice; and Prof. E. Isaac and Dr. E. Schelpe, Department of Botany. I am also indebted to the Ariti-Locust Research Centre for providing a grant for this work, and to the Nuffield Foundation for allowing me six months leave of absence. Full results have been deposited with the Anti-Locust Research Centre, British Museum (Natural History), London, S.W.7. H. B. D. KeTtLewell

Genetics Laboratory, Department of Zoology, University of Oxford. Jan 28.

' Kettlewell, H. B. D., Nature, 170, 584 (1952).

¿ Davey, J. T., Nature, 172, 720 (1953). Lea, A., Sci. Bull. Dep. Agric. S. Africa, No. 344 (Locust Research Series No. 15) (1953).

\section{Elution of Isoagglutinins adsorbed by Platelets}

The existence of $A, B, O$ and $A B$ groups in thrombocytes, corresponding to these groups in red blood cells, has been reported ${ }^{1,2}$. The identity of the $A$ and $B$ antigens in platelets and red blood cells has been proved by : (1) platelet agglutination with antisera; (2) cross-adsorption of isoagglutinins with thrombocytes and erythrocytes; (3) inhibition of isoagglutinins with saliva from secretors; and (4) neutralization of antisera with $A$ - and $B$-group specific substances. Similar results of agglutination of platelets were reported by Ruggieri and Bolognesi ${ }^{3}$. Adsorption of $A$ - and $B$-isoagglutinins with platelets was reported by Moureau and André4.

The present communication deals with studies on eluates of antisera adsorbed with large amounts of platelets. The method of elution used is based on that of Landsteiner and Miller ${ }^{5}$. Details of the preparation of platelet suspensions and sera have been described elsewhere ${ }^{2}$.

To a platelet sediment prepared from $40-50 \mathrm{ml}$. of blood, $0.5 \mathrm{ml}$. of normal saline was added, and the tube shaken gently for $3-5 \mathrm{~min}$. at about $6^{\circ} \mathrm{C}$., to obtain a homogeneous concentrate of platelets. This suspension was added to $0.7 \mathrm{ml}$. of a high-titred antiserum in a siliconed tube and left for $15-20 \mathrm{hr}$. at $6^{\circ} \mathrm{C}$, , being occasionally shaken. After centrifugation at 2,000 r.p.m. for 10 min., the adsorbed serum was pipetted off, and the platelet sediment washed three times in normal saline to ensure removal of traces of serum.

The washed platelet sediment was resuspended in $0.4 \mathrm{ml}$. of normal saline and vigorously shaken by hand in a water-bath at $56^{\circ} \mathrm{C}$. for $5 \mathrm{~min}$. It was then centrifuged at $56^{\circ} \mathrm{C}$. for 1 min. at 3,000 r.p.m. and the supernatant eluate was immediately removed. Special precautions were taken to ensure a constant temperature of $56^{\circ} \mathrm{C}$. during elution.

Using the above technique, eluates of fifteen different $A, B$ and $O$ sera were prepared and examined for agglutinating capacity against erythrocytes and thrombocytes. Typical results of elution experiments are given in Table 1.

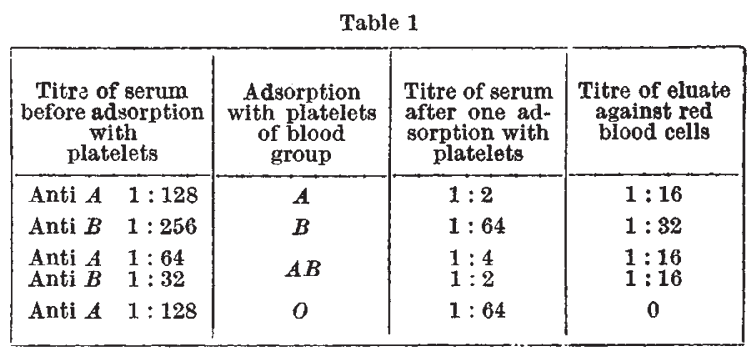

Eluates with a titre of $1: 16$ and higher also agglutinated platelet suspensions of the corresponding blood group.
J. GuRevitch
D. NELKEN

Hebrew University-Hadassah Medical School, Jerusalem.

Dec. 22.

${ }^{1}$ Gureviteh, J., and Nelken, D., Nature, 173, 356 (1954).

${ }^{2}$ Gurevitch, J., and Nelken, D., J. Lab. and Clin. Med., 44, 562 (1954).

${ }^{3}$ Ruggieri, P., and Bolognesi, G., Boll. Soc. Ital. Ematologia, 2, 127 (1954). 4 Moureau, P., and André, A., Vox Sanguinis, 4, 46 (1954); Nature,
174, 88 (1954).

${ }^{5}$ Landsteiner, K., and Miller, C. P., J. Exp. Med., 42, 852 (1925). 